Max-Planck-Institut für demografische Forschung

Max Planck Institute for Demographic Research

Konrad-Zuse-Strasse 1 - D-18057 Rostock · GERMANY

Tel +49 (0) 3812081 - 0; Fax +49 (0) 3812081 - 202;

http://www.demogr.mpg.de

MPIDR WORKING PAPER WP 2007-024

JUNE 2007

\title{
How fertility and union stability \\ interact in shaping new family patterns in Italy and Spain
}

Lucia Coppola (1coppola@istat.it)

Mariachiara Di Cesare (mariachiara.dicesare@uniroma1.it)

This working paper has been approved for release by: Hill Kulu (kulu@ demogr.mpg.de)

Deputy Head of the Laboratory of Contemporary European Fertility and Family Dynamics.

(C) Copyright is held by the authors.

Working papers of the Max Planck Institute for Demographic Research receive only limited review. Views or opinions expressed in working papers are attributable to the authors and do not necessarily reflect those of the Institute. 


\title{
HOW FERTILITY AND UNION STABILITY INTERACT IN SHAPING NEW
}

\section{FAMILY PATTERNS IN ITALY AND SPAIN}

\author{
Lucia Coppola $^{1}$ and Mariachiara Di Cesare ${ }^{2}$
}

\begin{abstract}
In this paper we investigate the interrelationships between fertility decisions and union dissolution in Italy and Spain. We argue that there might exist a spurious relationship between these two life trajectories. The analysis is based on the 1996 Fertility and Family Survey data for Italy and Spain. Results show that there is a spurious relationship between fertility and union dissolution in Italy but not in Spain. Nevertheless, in both countries, there is an evident direct effect of each process on the other: union dissolution decreases the risk of further childbearing, while childbirth decreases the risk of union dissolution.
\end{abstract}

${ }^{1}$ ISTAT, Via Adolfo Rava’ 150, 00142 Roma, Italy; lcoppola@istat.it

Dipartimento di Scienze Demografiche Universita’ di Roma “La Sapienza”, Via Nomentana 41, 00161 Roma, Italy; mariachiara.dicesare@uniroma1.it 


\section{INTRODUCTION}

Italy and Spain represent the so called "Mediterranean Model”, that in the framework of the Second Demographic Transition differentiates from Central and Northern European countries, for showing peculiars demographic trends (Van de Kaa 1987). In the Southern European countries, indeed, the transitions to union formation and parenthood have been dramatically postponed, and marriage and fertility have decreased as well, at level even lower than other countries. But, while in many Western countries cohabitation compensates the decline of marriages, and non-marital fertility as well as late age childbearing balances partly the decline in fertility, this does not happen in Italy and Spain (Lesthaeghe and Moors 2000). Italy and Spain are also similar in being characterized by very strong family ties, that often provide individuals with the social support not granted by their weak welfare states (Reher 1998).

In this paper we focus in particular on fertility decision and union instability. It is well known that these two countries are champions in Europe for having achieved nowadays the "lowestlow” levels of fertility (Kohler, Billari and Ortega 2002). In contrast, union instability although increasing, is still at very low levels if compared with other European countries (De Rose and Di Cesare 2003; Houle, Simo and Solsona 1999).

We argue that fertility decision and union instability are strongly interrelated trajectories that together shape one's family related life-course. Firstly, there might be a spurious relationship between these processes, because they might be simultaneously influenced by individual unobserved characteristics (Thornton 1977; Lillard and Waite 1993). Here we propose to interpret these characteristics in terms of value orientation: "family oriented” individuals are expected to be more likely to have children, and less likely to experience union dissolution, while "individualistic" people are expected to have lower fertility and higher union dissolution risks. Moreover, fertility and union stability are assumed to affect each other directly. Childbearing might induce a lower risk of union dissolution (Willcox 1891; White 1990) by providing the couple with shared goals and interest (Thornton 1977), and by representing important costs in case of a union dissolution (Burges and Wallin 1953; Becker 1991). Union dissolution might decrease the chance of further childbearing, because nonmarital fertility is very low (particularly in the case of Italy and Spain) (Conseil de l'Europe 2002), and by reducing the confidence in future unions' chances of surviving (Lillard and Waite 1993). 
In order to study union dissolution and fertility decision as interrelated processes, distinguishing between direct and indirect reciprocal effects, we apply simultaneous hazard models (Lillard 1993). In addition, we compare the results we would obtain disregarding the (potential) effect of unobserved common determinants on the trajectories under study. We use the data from the Family and Fertility Survey for the empirical analyses, for providing standardized and detailed information about the processes of interest in the two countries.

\section{UNION DISSOLUTION AND FERTILITY DECISION: INDIRECT AND DIRECT INFLUENCES}

When two individuals enter a formal union, either a marriage or cohabitation, they share a decision-making process relatively to the survival of the relationship itself, and to the procreation during the relationship. Keeping a stable and satisfactory relationship, and having children, might represent two important goals for a union. The importance of each of these goals (or of both them) would be strongly determined according to individual value orientation, attitudes and preferences (Lestaheghe and Moors 2002; Becker 1996).

Changes in value orientation, at a macro level, have been found responsible for the main demographic trends characterizing the Second Demographic Transition (Lesthaeghe and Van de Kaa 1986). The shift from materialistic to post-materialistic needs (Inglehart 1997) has contributed to developing an individualization process. An increasing emphasis has been progressively attributed to individual independence, freedom, autonomy, and selfdevelopment. Such kind of cultural changes would have played an important part in explaining the spread of new demographic behaviors, such as cohabitation, divorce, nonmarital fertility, pre-marital sex, and in postponing transitions implying high levels of commitment, as marriage and parenthood.

At a micro level, similarly, values, attitudes, preferences, influence individual's determination of only one specific life path, over the many possible alternatives (Barber, Axinn and Thorton 2002; Jansen and Kalmijn 2002; Bumpass 2002). Several life trajectories represent the different dimensions of a life-course. Thus, individuals decide about those trajectories coherently, according with own values, to achieve own specific goals (Lestaeghe and Moors 2002). For instance, individuals oriented towards family values are likely to decide about their employment, union, childbearing, and other careers, consistently to realize their family preferences. Thus, they might be likely to experience an early union formation (Baizan, Aasve and Billari 2003), and to invest many resources to achieve a stable and 
satisfactory relationship, trying to avoid or postponing union breakdown as long as there is a hope for recuperating the relationship (Bumpass 2002). They might also be likely to experience an early childbearing (Baizan et al. 2003), evaluating childbearing as a primary outcome of a union (Myers 1997; Jansen and Kalmijn 2002). In contrast, individuals oriented towards individualistic values might be more likely to give up a union as soon as it becomes problematic, or it affects negatively individual satisfaction and well being. They might also be less likely to invest in childbearing, being childbearing a time-consuming venture that necessarily reduces the amount of time at disposal.

We expect then that between union dissolution and fertility there might be a spurious relationship, i.e. these processes might be simultaneously determined according to same individual characteristics. In this paper these characteristics are treated as unobserved, and interpreted in terms of value orientation towards family vs. individualistic values. The formers are likely to invest more in fertility as well as in having a satisfactory relationship. The latter might be less willing to spend resources in family related issues, and in turn they might be more likely to experience union breakdown, and less likely to have children. Our first research hypothesis then follows:

\section{H1: Individuals more likely to have children are also less likely to experience} union dissolution (and vice versa).

Decision making processes develop over time, and having already made a decision about one process might determine the level of opportunity-cost of decisions belonging to other processes. Therefore, the outcome of a life trajectory process might directly affect the chance of experiencing an event pertaining to another trajectory (Lestaeghe and Moors 2002). Thus, for instance, been enrolled in education might reduce strongly the chance of entering a union or parenthood (Blossfeld and Huinink 1991; Coppola 2004). Similarly, we argue that not only fertility and union dissolution decisions might have common determinants, but also that the outcomes of these two processes might affect each other directly.

On the one hand, having children might affect union stability. Children have been shown to have an impact upon stability in several ways. By increasing marital satisfaction childbearing might promote union stability: children indeed may provide the partners with shared goals and interests which are translated into satisfaction and stability (Thornton 1977). The presence of children delays or prevent the break up of couples who are unhappily married (Thornton 1977), representing the cost of children an obstacle to union dissolution (Becker 
1991). In contrast, few children in the marriage represent weak attractions within the marriage, low barrier forces, and strong attractions outside the marriage (Wineberg 1988; White 1987; Levinger 1965, 1976). Also the parity of children might affect parental relationship (Levinger 1965, 1976; Thompton 1977; Becker 1991). Some authors show that a first child reduces divorce probability in the year following the birth (Waite and Lillard 1991; Waite, Haggstrom and Kanouse 1985; White and Booth 1985), while it is not visible for subsequent births. Thus, our second hypothesis follows:

H2: Having children reduces the risk of union dissolution, and a stronger effect is associated with the first childbirth

On the second hand, union dissolution might affect the chance of having a further childbearing for the original members of the couple. Lillard and Waite (1993) have shown that the risk of union dissolution delays the transition into parenthood, arguing that being children a commitment for the marriage, couples who believe they are likely to split up avoid or postpone the decision of having a further child. Such an effect is expected to be even stronger once the actual union dissolution is taken into account, instead of the risk of experiencing it. We assume that once a union comes to a break, former partners are much less likely to have a further child for two reasons. Firstly, given that children belong to a couple rather than to each of the partner, union disruption, and the consequent singleness, might strongly reduce individual willingness to have a child (Lillard and Waite 1993). Secondly, having experienced a union disruption might reduce also the chance and/or the desire of forming a new commitment, and the confidence in its stability, and in turn the chance of further childbearing (Lillard and Waite 1993). Thus, our third hypothesis follows:

\section{H3: Experiencing union dissolution decreases the risk of further childbearing}

\section{UNION DISSOLUTION AS A RELATIVELY NEW PHENOMENA IN ITALY AND SPAIN}

In modern societies, marriage is a voluntary association between persons. To it different costs of formation and disruption belong (Weiss and Willis 1993). From an economic point of view, the end of a marriage has two different causes. Firstly, the relationship with a partner could be upset when one of the members meets a new potential partner who increases this 
member's utility. Secondly, many events modify a marriage, which could lead both partners to break the union. The importance of these events depends on linked social problems. Union dissolution brings an end to the family and it may produce economic conditions that in general are insufficient in covering all members' needs. The solidarity and internal redistribution that are typical of the traditional family will no longer function and new economic differences will arise between family members (Sgritta 1993). The well-being of a single person rests on the community. The negative consequences of a dissolution often affect women disproportionately, as in general their economic situation is more precarious than that of men (Giddens 1989).

Rising divorce figures seem to be strongly related to changing gender systems and gender relations in society, such as the gradual elimination of gendered items in legal provisions and the growing tendency of women to take up paid employment (Lee 1982).

In Italy and Spain, marriage still seems to play an important social role. Cohabitation is not as common as in other European countries, also if it is visible an increase in the proportion of cohabitations (Sabbadini 1997; Tobio 2001). This is due to cultural factors as well as to the economic and social policies that favor marriage. However, this does not mean that union instability is absent. The slow but constant increase in the absolute number of union disruption is an indicator of changing family behavior (Figure 1).

We categorize the potentially explanatory variables of union dissolution in four groups: cultural, societal, dyadic and individual (Laner 1978).

Belonging to the first group, we consider the variable describing the period. We distinguish between two main periods: before the seventies and after the seventies. In Europe the 1970s and the first part of the 1980s witnessed important reforms in family law like the introduction of the divorce and the abortion. We considered that the process started in Italy in the first years of the 1970s (1970 divorce law) and in Spain (1981 divorce law) during the first years of the 80s have been the consequence of important changes in the values. The 1987 have been considered the boundary year between the old set of non secularized values and the new secularized ones. Moreover, in Italy the 1987 corresponds to a new reform of the divorce law, reducing from 5 to 3 the years of separation necessary to obtain the divorce. Another phenomenon related to change in attitudes and values is the spreading of consensual unions. Cohabitation is considered strictly correlated to higher probability of divorce (Bennett, Blanc and Bloom 1988; Booth and Johnson 1988; White 1987). Possibly, people who choose cohabitation do not accept normative marital behaviors, have lower commitment to marriage as an institution, and have more secularized values. 
For the description of the societal group we look at the role that paid employment plays in family dynamics (Bracher et al. 1993). In particular, we examine whether the presence of women in the labor market is associated with a higher risk of marital instability (Booth et al. 1984; Rank 1987; Spitze and South 1985) paying a particular attention to the amount of hours worked weekly, usually found positively correlated to union dissolution (Hill 1988; Spitze and South 1985).

In the dyadic group, the core of this research is considered according to what discussed in the previous section, i.e. the fertility behaviour.

Concerning the individual group we consider three main variables. Firstly, the age at union formation. The younger the person is at the time of union formation, the higher the union instability (Morgan and Rindfuss 1985, South and Spitz 1986; Thornton and Rodgers 1987; Martin and Bumpass 1989). Secondly, the inheritance of divorce behavior (Mueller and Pope 1976; Greenberg and Nay 1982; McLanahan and Bumpass 1988). Parental separation is likely to lead to the offspring leaving home earlier and forming a union more quickly than those whose parents have never separated. In this case, there is a higher percentage of cohabitation compared to marriage. Finally, we consider the role of education on the couple's stability: usually the higher the educational level, the more likely an individual adopts nontraditional behavior (Becker 1991; Blossfeld, De Rose and Hoem 1993; Blossfeld and Huinink 1991).

\section{FERTILITY AND THE LOWEST-LOW LEVELS REACHED IN ITALY AND SPAIN}

Fertility is the result of a complex decision making process dealing with when and how many children an individual, or more usually a couple desires and can actually have. Much emphasis has been given to the trend of first childbearing postponement characterizing the western countries during the last decades (Van de Kaa 1987). Such a trend, in the framework of the general postponement of the transition to adulthood, finds explanations in the change of values increasingly emphasizing post-materialist needs and individual autonomy, selfrealization and well-being (Inglehart 1997). In addition, a prolonged educational process (Blossfeld and Huinink 1991; Coppola 2004), an increasingly unstable labor market and the youth’s economic uncertainty (Oppenheimer 1988; Oppenheimer and Lew 1995), a women’s rising participation to labor force (Becker 1991), have contributed to delay the transition into parenthood. 
Italy and Spain are characterized simultaneously by an evident postponement of parenthood as well as a progressively reduction of the total fertility, becoming champions in lowest-low fertility (Kohler et al. 2002). In these two countries fertility has shown a decline between years (Figure 2) and between generations. These trends are partly explained by an extremely evident postponement of the transition to adulthood, and by a the difficulties new family habits face to spread, as shown by the scarce diffusion of cohabitation, and out of wed-lock childbirths (Lesthaeghe and Moors 2000; Conseil de l'Europe 2002). As a consequence young individuals enter a marital union later and less, and childbearing take place later and less.

Among the characteristics likely to influence one's fertility decisions we consider the cohort, because among young cohorts it is visible an attitude to postpone the first child compared with older generations. But once they have had the first child, they are increasingly having a second or a third, even if these births are postponed longer than before (Pinnelli et al. 2001). Women's educational level is considered as one of the main causes of union formation postponing and consequently childbearing postponing (Blossfeld and Huinink 1991; Knudsen 1996; Di Giulio et al. 1999). Generally the attainment of a medium or high level of education is associated with a lower and later fertility. In particular, a medium level of education is more likely to have an impact on the quantum of fertility, leading more often to the decision of not having children at all. A high level of education is more likely to impact on timing, but it is less often an impediment to eventual childbearing (Pinnelli et al. 2001).

Women's employment has usually and evident impact on fertility decisions, inducing women to have less children and later (Butz and Ward 1979; Lesthaeghe and Moors 1995; Kohler et al. 2002). This is especially true in Italy and Spain, where the labor market is characterized by high levels of rigidity basically due to very similar patterns of employments for women and men (Angeli, De Rose and Di Cesare 2004). Conform to McDonald's (2000) research, fertility falls to very low levels when gender equity rises in individual oriented institution, like the labor market, but not in family oriented institutions. On the one hand, in Italy and Spain there are not special employments for women who want to reconcile work with family commitments. On the other hand, family roles in these two countries have been slow in adapting to women's new roles in the labor market (Chesrais 1996), and it is visible a highly asymmetric labor division within households, which becomes even more asymmetric after the birth of the first child (Palomba and Sabbatini 1993). In addition the very low level of institutional and social support to family (Reher 1998) means that more often women have to choose between employment and maternity, as not easily compatible alternatives. 
As regards the relation between partners, we consider the type of union. In fact, it has been demonstrate that the transformation of cohabitation into marriage has a positive effect on fertility (Pinnelli et al. 2001). Also a couple's separation is taken into account, according to what discussed in section 2.

As far as the fertility process is concerned, we consider the age at childbirth, and the birth order. In Italy and Spain the probability of deciding to have a child decreases with age for all birth orders (Pinnelli, Hoffmann-Nowotny and Fux 2001). A negative association between the age at first birth and completed fertility has been found (Bumpass and Mburugu 1977; Marini and Hodsdon 1981; Morgan and Rindfuss 1985; Kohler et al. 2002). This is true also because fertility starts to fall with age from as early as 25, and more rapidly from 35 onwards (Menken and Larsen 1994; Wood 1994; Beets 1995), an age at which it has become increasingly common to start forming a family. Finally, it has been found that the higher the birth order, the lower is the chance of having a further child (Pinnelli et al. 2001).

\section{DATA AND METHODS}

The analysis is based on the 1996 Fertility and Family Survey (FFS) data for Italy and Spain. This survey was conducted in the 1990s in many member states of the United Nations Economic Commission for Europe and was coordinated by the Population Activities Unit (PAU). The survey provides a (bigger) samples of women, a (smaller) sample of men, as well as a third sub-sample of the current partners of women' s interviewed. In this paper, we use the independent female sample. We select a sub-sample of women who have experienced first union formation, so to focus on individuals simultaneously exposed at risk of childbearing and of union dissolutions. The exclusion of women not in a union does not affect the analysis of fertility process, out of wed-lock childbearing being extremely rare in Italy and Spain. We have not considered unions ended by the death of partner, because these cases are so few that their omission does not influence the analysis in any way. We consider first unions, not distinguishing between cohabitation and marriage, because we are interested in taking under control both types of union, since cohabitation, even if not widespread among the population, is a phenomenon of increasing importance among the youngest generations interviewed in the survey. Union dissolution is defined as when the partners do not longer live together.

We have argued that between union dissolution and fertility decision there might exist a spurious relationship (i.e. there might be some unobserved common determinants of both 
processes), as well as direct reciprocal causality. In order to verify whether our hypotheses of research hold in the context of Italy and Spain, we use simultaneous hazard modeling (Lillard 1993). Each process is represented through a continuous hazard equation. The outcome of each process is introduced as a explanatory variable of the other process, to control explicitly for their mutual effect. The effect of unobserved characteristics on each process is represented through a heterogeneity term. Allowing for correlation between the two heterogeneity terms we control for the effect of potentially common unobserved determinants of both processes (Baizan et al. 2003; Coppola 2004). Formally the models can be presented as follows:

$$
\left\{\begin{array}{l}
\ln h^{f}(t)=\alpha_{0}+D_{f}(t)+A_{f}(t)+\alpha_{1} X(t)+\alpha_{2} \operatorname{Diss}_{f}(t)+\varepsilon_{f} \\
\ln h^{d}(t)=\beta_{0}+D_{d}(t)+\beta_{1} Y(t)+\beta_{2} \operatorname{Fer}(t)+\varepsilon_{d}
\end{array}\right.
$$

where $h^{f}(t)$ is the hazard rate of experiencing a further childbearing; $D_{f}(t)$ is the spline (with knots at 12, 24 and 36 months) representing the duration of the exposure to the risk of having a child since the union formation (for the first parity) or since the previous childbirth (for the following parities); $A_{f}(t)$ is the spline (with knots at 23 and 28 years) representing the age of the woman at the event; $X(t)$ is the set of time constant or time varying explanatory variables we include in the model: cohort, educational level, employment, birth order and marriage; $\operatorname{Diss}_{f}(t)$ is the time varying variable indicating whether the union dissolution occurs (through this variable we control for the direct effect of the other process); $\varepsilon_{f}$ is the heterogeneity term representing the effect of the unobserved characteristics on the process. Similarly, $h^{d}(t)$ is the hazard rate of experiencing union dissolution; $D_{d}(t)$ is the spline (with knots at 38, 84, and 180 months) representing the duration of the exposure to the risk of union dissolution since the first union formation; $Y(t)$ is the set of explanatory variables we include in the model: age at first union, educational level, employment, marriage, historical period, parents' separation; $\operatorname{Fer}(t)$ is the time varying variable indicating whether and how many children the woman has; $\varepsilon_{d}$ is the heterogeneity term.

Allowing for correlation between the heterogeneity terms $(\rho)$ is crucial to control for the (potentially) simultaneous effect of the unobserved characteristics on both processes. Thus, the error terms are assumed to be time constant and distributed according to a bivariate normal distribution as follows: 


$$
\left(\begin{array}{l}
\varepsilon_{f} \\
\varepsilon_{d}
\end{array}\right) \cong N\left(\left(\begin{array}{l}
0 \\
0
\end{array}\right),\left(\begin{array}{cc}
\sigma_{f}^{2} & \rho \sigma_{f} \sigma_{d} \\
\rho \sigma_{f} \sigma_{d} & \sigma_{d}^{2}
\end{array}\right)\right)
$$

The models are estimated at maximum likelihood, using the aML software package (Lillard and Panis 2000).

\section{RESULTS}

We show three different estimated models (Table 1 and 2): firstly we have estimated the equations, representing the two processes under study, separately and without including the error terms; secondly we have included the error term in each equation; finally we have estimated the two equations simultaneously, allowing for the correlation between the two processes ${ }^{1}$. We show the three approaches to provide a better description of if and how much using simultaneous modeling results to be worthwhile, when investigating the interrelationships between fertility and union dissolution in Italy and Spain.

\subsection{UNOBSERVED DETERMINANTS OF FERTILITY AND UNION DISSOLUTION}

The estimates obtained through the simultaneous approach are shown below Model 3, in Table 1 for Italy and Table 2 for Spain. We discuss the estimates of the simultaneous modeling first, and the estimates obtained excluding the heterogeneity terms (model 1), or the correlation between them (model 2) in comparison. Whether there exists or not a spurious relationship between union dissolution and fertility is indicated by the estimate of the correlation between the heterogeneity terms $(\rho)$. The results show that there exists a negative and significant correlation between the unobserved affecting union dissolution and those affecting fertility in the case of Italy. In Spain, instead, such a correlation is still negative but no longer significant. Thus, our first hypothesis (H1) finds empirical evidence in Italy but not in Spain. In the former country, individuals more likely to experience union dissolution are less likely to have a further child (and vice versa). In the latter country, there is not any

\footnotetext{
${ }^{1}$ When estimating the simultaneous model, the variance of the heterogeneity term of the union dissolution process $\sigma_{d}^{2}$ is fixed. Since changing the variance does not have a significant impact on the parameter estimates, we prefer to set such a value at the same level obtained when modelling the union dissolution process alone.
} 
indirect effect between the processes once their reciprocal direct effect and the other individual characteristics are controlled for. Thus, in the case of Italy the use of simultaneous modeling provides a better description of the processes under study and of their interrelationship. In the case of Spain, instead, such modeling approach does not provide any further information if compared with the modeling where correlation is not allowed (Model 2). As a consequence, also the estimates of the direct effect of each process on the other are quite different when using simultaneous modeling in Italy, while they are very similar even if using the different approaches in Spain.

Concerning the effect of fertility on union dissolution, we notice that in Italy having a further child decreases significantly the risk of union dissolution when the spurious relation is disregarded (see Model 1 and 2), while such an effect is much smaller and less significant when simultaneous modeling is used (see Model 3). Indeed, when using the simultaneous approach, only the second or higher parities are associated with a significantly lower risk of union disruption. Thus, it is not the fact of having a child itself to induce a lower risk of union dissolution, but also those individual unobserved characteristics that induce women to have a higher fertility as well as a higher union stability. In Spain, fertility induces a significantly lower risk of union dissolution only in the case of the second parity, independently on the modeling approach used. Thus our second hypothesis (H2) is only partly confirmed, given that fertility actually induces a lower risk of union dissolution, but this effect is lower than expected. Moreover, while such an effect increases with the parity in Italy, it is not true in Spain. Thus the stronger effect is not associated with the first parity as assumed.

With regard to the effect of union dissolution on fertility, in both countries a union breakdown induces a much and significantly lower risk of having a further child. Thus, our third hypothesis (H3) is confirmed in both Italy and Spain. As argued before, when the simultaneous approach is used the direct effect of union dissolution on fertility is slightly lower in the case of Italy.

\subsection{UNION DISSOLUTION}

In this section, and in the next one, we briefly discuss the effects of the control variables we have introduces in the models. Duration of the union: There is not a well defined shape of the risk of union dissolution by duration. In Spain it is visible a higher risk in the first years of the union and a significant decrease after 7 years of union, while in Italy the risk increases 
significantly between the $7^{\text {th }}$ and the $15^{\text {th }}$ years of union and decreases after $15^{\text {th }}$ years. But in both countries the effect is very small.

Age at union formation: in both countries there is a quite strong effect of this variable on the union stability. Women aged less then 20 have a higher risk of their union ending than do women aged 20 or over. The general trend in both countries is that the higher the age at union formation, the lower the risk of union dissolution. However, the decrease in risk is more pronounced during relatively young ages.

Parents separation: the parent's separation affects the risk of instability, confirming the strong relationship between parents' separation and disequilibrium within the children's first union, also in Italy and Spain. It is also likely that an experience of parental separation affects the value and the meaning individuals attribute to partnership. The age at which children experience their parents' separation has also an impact on the future risk of their separation or divorce. Experiencing parental union disruption during childhood increases significantly and strongly one's own risk of union disruption. Such an effect becomes not significant if parents' separation occurs when the "child” has become an adult (age>18 years).

Education: in both countries, there is a significant effect of education on the risk of union dissolution. This variable is used as an indicator of the changed status of women in society. In Italy, the higher is the educational level of women, the higher is the risk of union dissolution. In Spain the higher risk of union dissolution is associated with a medium level of education. Type of union: we have considered marriage as a reference category so as to pick up the effect of cohabitation. Marriage represents one of the elements of union stability (in both cases: with or without previously cohabitation). This strong difference in the risk between the two kinds of union is linked to the meaning of cohabitation. Cohabitation does not have a legally recognized status in Italy and Spain. Cohabiters do not have mutual rights and duties and either party may consider ending the relationship at any time. The absence of any legal or recognized protection automatically gives instability to this kind of union. Hence, cohabitations have a much higher risk of breakdown than marriages in both countries.

Employment: being employed induces a higher risk of union disruption for women when compared with the unemployed and housewife category. This conclusion is valid when looking at the whole category of employed people. Considering subgroups by hours of work, we notice that the group of women that work more than 45 hours a week, experience a much higher risk of union dissolution. This in true in both countries, and in Italy the difference with the other categories is wider. This result confirms our assumption that the absence of union stability is strictly linked to the new behavior and habits accessible to women. The changing 
behavior of women has not been matched by the necessary changes needed in a relationship. If the woman is not at home for many hours, it represents a shock to the equilibrium of the couple.

Period: the process of secularization is associated with an increase in union instability, but such an effect appears to be stronger in Italy. This is probably due to the fact that in Italy divorce has been allowed earlier than in Spain.

\subsection{FERTILITY}

Duration: The risk of having a child by the duration since the beginning of the union (for the first parity), or the previous birth (for the following parities) shows a similar pattern in both countries. It rises during the first year, then it decreases during the second year, it rises again during the third year, and decreases later on. In both countries, when considering simultaneous modeling (Model 3), the decrease during the second year loses significance, suggesting a reverse $\mathrm{V}$ shape with a knot at the end of the third year.

Age at childbirth: the higher is the age at childbirth, the lower is the risk of having a further childbirth. Such a trend is significant and strong in both countries.

Cohort: broadly speaking the more recent is the cohort, the lower is the risk of a further childbearing in both countries. The youngest Spanish cohort represents an exception to this trend role, in fact the negative effect of the cohort is weaker than that of the previous cohorts and it is quite similar to that of the Cohort 56-60. It is probably due to a change in attitudes of the youngest generations. The cohort effect is stronger when including the heterogeneity (Model 2) and the correlation (Model 3). When controlling for the effect of unobserved determining a higher predisposition towards high fertility, the decrease in the risk of having a further childbirth by cohort is more evident. Possibly the effect of reducing fertility, due to changes in terms of culture, values, and socio-economic context faced by the different generation appears more clearly.

Education: education affects the risk of a further childbirth as we expected. In Italy, having a medium level of education is associated with a lower fertility much more than a high level of education. Higher educational levels might be associated with other individual characteristics and resources that ease women's reconciliation of family related and non family related roles (i.e. higher economic resources, more flexible position in the labor market). This is not true in Spain, where the higher is the educational level, the lower is the chance of a having a further child. 
Employment: When increasing the number of working hours per week, the probability to have a further child decreases. Only in Italy, a slight recover for women who work for many hours (more than 45) is visible; the explanation could be find in the major financial resources of these women, that allow them to afford all the services they need to conceal employment and fertility. The main difference between the two countries is represented by the category of the self-employed workers: while in Italy they have the lowest probability to have a next child, in Spain self-employed women have the second highest probability, after the category of housewife. It could be due to country differences in the composition of the category of selfemployment. Self-employment in Spain might allow for a higher flexibility and in turn to an easier conciliation of employment a fertility.

Parity: in both countries, the higher is the parity, the lower is the risk to have a further child. Thus, women in a union actually aim to have at least one child, but not necessarily more than one.

Type of union: married women have a much higher risk of having a further child than cohabiting women do, and this is true in both countries. Such a result confirms that in Italy and Spain fertility is phenomena mainly associated with a traditional family structure, and with high levels of formalized commitment.

\section{DISCUSSION}

We have argued that fertility decision and union dissolution are two individual trajectories deeply interrelated (Lillard and Waite 1993), because both them contribute to define one's family related life course. Having one or more children and a stable relation and satisfactory relationship are indeed two of the main goals of an individual once he or she enters a union, either a cohabitation or a marriage. Thus, there might be some unobserved characteristics that might affect simultaneously individual decision about having a further child, and about giving up a relationship (Lillard and Waite 1993; Thornton 1977). We have proposed an interpretation of these unobserved characteristics potentially affecting decision making process about both trajectories in terms of individual value orientation. This interpretation belongs to the reasoning that actually values orientation contributes to determine the spreading of new demographic behaviors at macro level (Lesthaeghe and Moors 2002), and influence individual decisions about different life trajectories at micro level (Jansen and Kalmijn 2002). We have argued that possibly individuals are oriented towards family values or, in alternative, individualistic values. The formers are more likely to invest more resources 
in the family (Jansen and Kalmijn 2002). Thus, they might behave in order to realize a higher fertility, and achieve a satisfactory and stable relationship. In contrast, individualistic persons are less likely to invest in time and resources consuming activities, as children and a relationship are, and therefore they might behave in order to have less children, and give up a relationship as soon as it is not enough satisfactory.

Our arguments find empirical evidence in Italy where women who for unobserved individual characteristics are more likely to have a further child, are also less likely to experience union dissolution. Thus, we interpret that the Italian women oriented towards family are prone to have more children, and a stable relationship, while those oriented towards individualistic values have a lower fertility and a higher chance to breakdown their relationship. This result holds also if the direct effect of the outcome of each process on the other, as well as the other individual characteristics affecting the processes under study, are taken into consideration.

In the case of Spain, instead, the effect of unobserved characteristics or, according to our interpretation, of value orientation is not worth of consideration once the direct effect between union dissolution and fertility, and the other individual characteristics influencing these trajectories, are controlled for. We suggest that this result does not imply that value orientation does not influence individual behavior in Spain, but only that once the effect of other individual characteristics and life trajectories (i.e. education, employment, union formation) are explicitly considered, then the explanatory power left to values is much smaller than in Italy.

Nevertheless, as we assumed, in both countries there exists a direct effect between fertility decisions and union dissolution. On the one hand, having a child decreases the risk of union disruption, even if such an effect is lower that what expected. Thus, children represent a strong tie for the couple, providing shared goals and interests to the partners (Thornton 1977), as well as an economic obstacle to union dissolution (Becker 1991). On the other hand, union dissolution strongly decreases the risk of further childbearing. A union breakdown represents an obstacle to further fertility, by removing for a time the natural environment for having children, and by potentially reducing individual confidence in the stability of the next relationship, that in turn decreases the chance of having further children (Lillard and Waite 1993).

Italy and Spain are usually considered very similar countries not only because of the demographic patterns they witness (Van de Kaa 1987), but also for the welfare states they rely on, and the roles played by the different institutions (Esping-Andersen 1999). Among these, for instance, the family is fundamental in both countries, because through solid ties, it 
provides strong support to individuals when facing transitions and important life experiences (Reher 1998). For these reason when investigating demographic processes in these countries usually same results are expected. In our case, this is partially confirmed, because union dissolution and fertility appear to be affected by individual characteristics and by each other in a similar manner. However, the existence of a spurious relationship between union dissolution and fertility, that we were expecting in both countries, finds confirmation only in Italy. Such a difference might belong to those country differences that, even if much smaller if compared with other western countries, still hold. It would be interesting to dedicate future research focusing on the differences between these countries instead of their similarities. The comprehension of what makes the difference in similar contexts might provide a better inside in the phenomena under study. 


\section{REFERENCES}

Angeli, A., A. De Rose, and M. Di Cesare. 2004. "Prima e Dopo lo Scioglimento dell'Unione: Istruzione, Lavoro e Differenze di Genere.” Pp. 171-98 in Nuovi Comportamenti Familiari e Nuovi Modelli: Italia ed Europa a Confronto, edited by Heuresis Scienze Statistiche, CLUEB.

Baizan, P., A. Aasve, and F. Billari. 2003. "Cohabitation, Marriage and First Birth: the interrelationship of Family Formation Events in Spain." European Journal of Population 19:147-169.

Reed, W.R. and K. Harford. 1988. "The Marriage Premium and Compensating Wage Differentials.” Journal of Population Economics 2:237-265.

Barber, J.S., W.G. Axinn, and A. Thorton. 2002. "The Influence of Attitudes on Family Formation Processes.” Pp. 45-95 in Meaning and Choice: Value Orientations and Life Course Decisions, edited by R. Lesthaeghe. The Hague/Brussels: NIDI/CBGS Publications.

Becker, G.S. 1991. A Treatise on the Family. Cambridge: Harvard University Press.

Becker, G.S. 1996. Accounting for Tastes. Cambridge: Harvard University Press.

Becker, G.S., E.M. Landes, and R.T. Michael. 1977. “An Economic Analysis of Marital Instability.” Journal of Political Economy 85:1141-1188.

Pinnelli, A., H.J. Hoffmann-Nowotny, and B. Fux. 2001. Fertility and New Types of Households and Family Formation in Europe, Population Studies 35, Council of Europe Publishing.

Beets, G. 1995. "Does the Increasing Age at First Birth Lead to Increases in Involuntary Childlessness?.” in Evolution or Revolution in European Population. European Population Conference.

Bennett, N.G., A.K. Blanc, and D.E. Bloom. 1988. "Commitment and the Modern Union: Assessing the Link Between Premarital Cohabitation and Subsequent Marital Stability.” American Sociological Review 53:127-138.

Blossfeld, H.P., A. De Rose, J.M. Hoem, and G. Rowher. 1995. "Education, Modernization and the Risk of Marriage Disruption in Sweden, West Germany and Italy.” P.p 200-22 in Gender and Family Change in Industrialized Countries, edited by Oppenheim Mason K. \& A.M. Jensen. Oxford: Clarendon Press.

Blossfeld, H.P. and J. Huinink. 1991. "Human Capital Investments or Norms of Role Transition? How Women's Schooling and Career Affect the Process of Family Formation.” American Journal of Sociology 97:143-168.

Booth, A. and D. Johnson. 1988. "Premarital Cohabitation and Marital Success.” Journal of Family Issues 9:67-75.

Booth A., D. Johnson, L. White, and J. Edwards. 1986. "Divorce and Marital Instability 
over the Life Course.” Journal of Family Issues 7:421-442.

Bracher, M., G. Santov, S. Morgan, and J. Trussell. 1993. "Marital Dissolution in Australia: Model and Explanation.” Population Studies 47:403-425.

Bumpass, L. 2002. "Family-related Attitudes, Couple Relationships and Union Stability." Pp. 161-18 in Meaning and Choice: Value Orientations and Life Course Decisions, edited by R. Lesthaeghe. The Hague/Brussels: NIDI/CBGS Publications.

Bumpass, L. and E.K. Mburugu. 1977. "Age at Marriage and Completed Family Size.” Social Biology 24(1):31-37.

Burgess, E.W. and P. Wallin. 1953. Engagment and Marriage. Philadelphia: J.B. Lippincott Company.

Butz, W.P. and M.P. Ward. 1979. "Baby Boom and Baby Bust: a New View.” American Demographics 1(8):11-17.

Chesnais, J.C. 1996. "Fertility, Family, and Social Policy in Contemporary Western Europe.” Population and Development Review 22(4):729-739.

Conseil de l’Europe. 2002. Evolution Dèmographique Rècente en Europe.

Coppola L. 2004. "Education and Union Formation as Simultaneous Processes in Italy and Spain.” European Journal of Population 20: 219-250.

De Rose, A. and M. Di Cesare. 2003. "Genere e scioglimento della prima unione.” pp. 339-366 in Genere e Demografia, edited by A.Pinnelli, Bologna: il Mulino.

Di Giulio, P., R. Lesthaeghe, R. Moors, and A. Pinnelli. 1999. "Fertility Tempo and Quantum: an Empirical Test of Major Theories with Data from Four Ffs Countries.” in Démographie, Analyse et Synthèse, Actes du Séminaire de RomaNapoli-Pozzuoli, 2, DSD-INED, Roma-Paris.

Esping-Andersen G. 1999. Social Foundations of Postindustrial Economies. Oxford: Oxford University Press.

Giddens A. 1991. Sociologia. Bologna: Il Mulino.

Greenberg, E.F. and wW.R. Nay. 1982. "The Intergenerational Transmission of Marital Instability Reconsidered.” Journal of Marriage and the Family 44:335-347.

Hill M. 1988. “Marital Stability and Spouses’ Shared Time.” Journal of Family Issues 9:427-451

Houle R., C. Simo, and M. Solsona. 1999. "Separation and Divorce in Spain.” Southern European Society and Politics, 194-221.

Inglehart, R. 1997. Modernization and Postmodernization. Cultural, Economic, and Political Change in 43 Societies. Princeton: Princeton University Press.

Jansen, M. and M. Kalmijn. 2002. "Investments in Family Life: the Impact of Value 
Orientations on Patterns of Consumption, Production and Reproduction in Married and Cohabiting Couples.” Pp: 129-159 in Meaning and Choice: Value Orientations and Life Course Decisions edited by R. Lesthaeghe. The Hague/Brussels: NIDI/CBGS Publications.

Knudsen, L.B. 1996. "Do gender-specific differences in fertility pattern in Denmark reflect different expectation to men and women?.” in Evolution or Revolution in European Population. European Population Conference, Vol.2 Milan: Franco Angeli

Kohler, H.P., F.C. Billari, and J.A. Ortega. 2002. "The Emergence of Lowest-Low Fertility in Europe During the 1990s.”, Population and Development Review 28(4):641-680.

Laner, M. 1978. “Love’s Labor Lost: A Theory of Marital Dissolution.” Journal of Divorce 1:213-232.

Lee, G. 1982. Family structure and Interaction: A Comparative Analysis. Minneapolis: University of Minnesota Press.

Lesthaeghe, R. and G. Moors. 1995. "Is There a New Conservatism that Will Bring Back the Old Family? Ideational trends and the stages of family formation in Germany, France, Belgium and the Netherlands, 1981--1990.” Pp. 225-266 in Evolution or Revolution in European Populations, European Population Conference, Milan: Franco Angeli.

Lesthaeghe, R. and G. Moors. 2000. "Recent Trends in Fertility and Household Formation in the Industrialised World.”, IPD Working Paper 2000-2, Brussels: Free University Brussels.

Lesthaeghe, R. and G. Moors. 2002. "Life Course Transitions and Value Orientations: Selection and Adaptation.” Pp. 1-44 in Meaning and Choice: Value Orientations and Life Course Decisions, edited by R. Lesthaeghe. The Hague/Brussels: NIDI/CBGS Publications.

Lesthaeghe, R. and J. Surkyn. 1988. "Cultural Dynamics and Economic Theories on Fertility Change.” Population and Development Review 14:1-45.

Lesthaeghe, R. and D. Van de Kaa. 1986. "Twee demografische transities?.” Pp. 9-24 in Bevolking: groei en krimp, Boekaflevering Mens en Maatschappij, edited by D. Van de Kaa D and R. Lesthaeghe. Deventer: Van Loghum Slaterus.

Lesthaeghe, R. and C. Vanderhoeft. 1997. "Ready, Willing and Able. A Conceptualization of Transitions to New Behavioral Forms.” IPD Working Paper 1997-8, Brussels: Free University Brussels.

Levinger, G. 1965. "Marital Cohesiveness and Dissolution: an Integrative Review.“ Journal of Marriage and the Family 27:19-28.

Levinger, G. 1976. “A Social Psychological Perspective on Marital Dissolution.” Journal of Social Issues 32:21-42.

Lillard, L.A. and C.W.A. Panis. 2000. aML Multilevel Multiprocess Statistical Software, 
Release 1.0. Los Angeles, California, EconWare.

Lillard, L.A. and L.J. Waite. 1993. :A Joint Model of Marital Childbearing and Marital Disruption.” Demography 30(4):653-681.

Marini, M.M. and P.J. Hodsdon. 1981. "Effects of the Timing of Marriage and First Birth on the Spacing of Subsequent Births.” Demography 18(4):529-548.

Martin, T.C. and L. Bumpass. 1989. "Recent Trends in Marital Disruption.” Demography 26:37-51.

McDonald, P. 2000. "Gender Equity in Theories of Fertility Transition.” Population and Development Review 26(3):427-440.

McLanahan, S. and L. Bumpass. 1988. "Intergenerational Consequences of Family Disruption”. American Journal of Sociology 94:130-152.

Menken, J. and U. Larsen. 1994. "Estimating the Incidence and Prevalence and Analysing the Correlates of Infertility and Sterility." Annals of the New York Academy of Sciences 709:249-265.

Morgan, S.P. and R.R. Rindfuss. 1985. "Marital Disruption: Structural and Temporal Dimensions.” American Journal of Sociology 90:1055-1077.

Mueller, C.W. and H. Pope. 1976. "The Intergenerational Transmission of Marital Instability: Comparisons by Race and Sex.” Journal of Social Issues 32:49-66.

Oppenheimer, V.K. 1988. “A Theory of Marriage Timing.” American Journal of Sociology 94: 563-591.

Oppenheimer, V.K. and V. Lew. 1995. "Marriage Formation in the Eighties: How Important was Women’s Economic Independence?.” Pp. 105-138 in Gender and Family Change in Industrialised Countries, eedited by K.O. Mason and A. Jensen. Oxford: Clarendon Press.

Palomba, R. and L.L. Sabbadini. 1993. "Female Life Strategies: the Way of Compromise.” Proceedings of the XXIII IUSSP General Conference, Montreal 2: 219-231.

Rank, M. 1987. "The Formation and Dissolution of Marriages in the Welfare Population.” Journal of Marriage and the Family 49:15-20.

Reher, D.S. 1998. “Family Ties in Western Europe: Persistent Contrasts.” Population and Development Review 24: 203-234.

Sabbadini, L.L. 1997. "Le Convivenze "More Uxorio””. Pp. 86-94 in Lo Stato delle Famiglie in Italia edited by Barbagli, M. and C. Saraceno. Bologna. Il Mulino.

Sgritta G.B. 1993. “Divorzio.” Pp. 231-242 in Enciclopedia delle Scienze Sociali, Roma, IEI.

South, S. and G. Spitze. 1986. "Determinants of Divorce over the Marital Life Course.” 
American Sociological Review 51:583-590.

Spitze, G. and S. South. 1985. "Women’s Employment, Time Expenditure, and Divorce.” Journal of Family Issues 6:307-329.

Thornton, A. 1977. “Children and Marital Stability.” Journal of Marriage and the Family 39(3):531-540.

Thornton, A. and W. Rodgers. 1987. "The Influence of Individual and Historical Time on Marital Dissolution.” Demography 24:1-22.

Tobio, C. 2001. "Marriage, Cohabitation and the Residential Independence of Young People in Spain”. International Journal of Law, Policy and the Family, 15:68-87.

Van de Kaa, D.J. 1987. “The Second Demographic Transition” Population Bulletin 42, Washington D. C.: Population Reference Bureau.

Waite, L.J. and L.A. Lillard. 1991. "Children and Marital Disruption.” American Journal of Sociology 96(4):930-953.

Waite, L.J., G.W. Haggstrom, and D.E. Kanouse. 1985. "The Consequences of Parenthood for the Marital Stability of Young Adults.” American Sociological Review 50(6):850-7.

Myers, S.M. 1997. “Marital uncertainty and childbearing.” Social Forces 75:1271.

Weiss, Y. and R.J. Willis. 1993. "Transfers among divorced couples: evidence and interpretation.” Journal of Labor Economics 11(4):629-79.

White, J. 1987. "Premarital Cohabitation and Marital Stability in Canada." Journal of Marriage and Family 49:641-647.

White, L.K. 1990. "Determinants of Divorce: a Review of Research in the Eighties." Journal of Marriage and the Family 52:904-912.

White, L.K. and A. Booth. 1985. "The Quality and Stability of Remarriages: the Role of Stepchildren.” American Sociological Review 50(5):689-98.

Willcox, W.F. 1891. The Divorce Problem, A Study in Statistics. New York: Columbia University Press.

Wineberg, H. 1988. "Duration between marriage and first birth and marital stability." Social Biology 35:91-102

Wood, J.W. 1994. Dynamics of Human Reproduction: Biology, Biometry, Demography. Hawthorne, NY: Aldine de Gruyter 
FIGURE 1. TOTAL DIVORCE RATE IN SOME EUROPEAN COUNTRIES YEARS 1960-2001

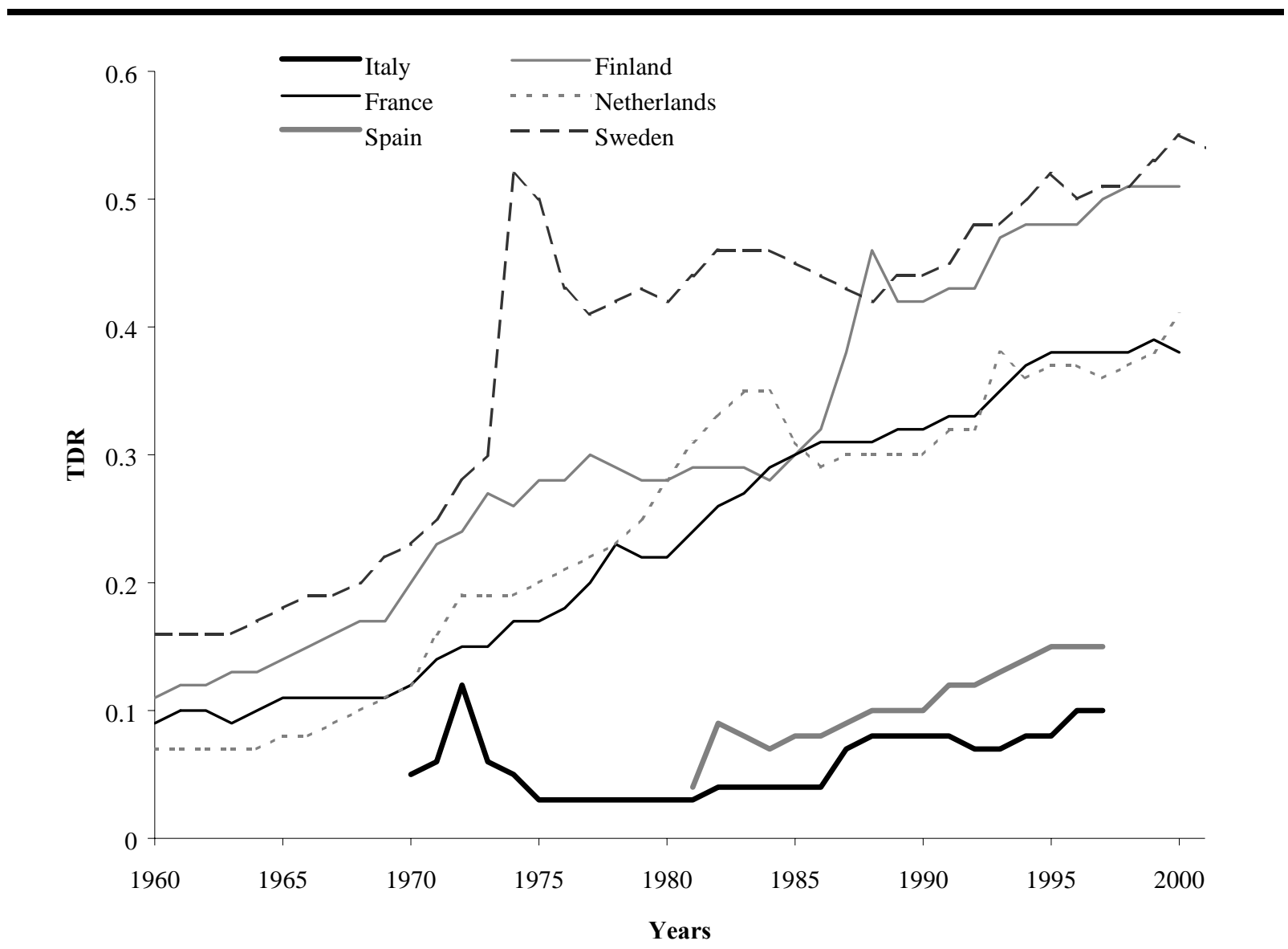

Source: Council of Europe - Demographic Yearbook 2002 
FIGURE 2.- TOTAL FERTILITY RATE IN SOME EUROPEAN COUNTRIES YEARS 1960-2001

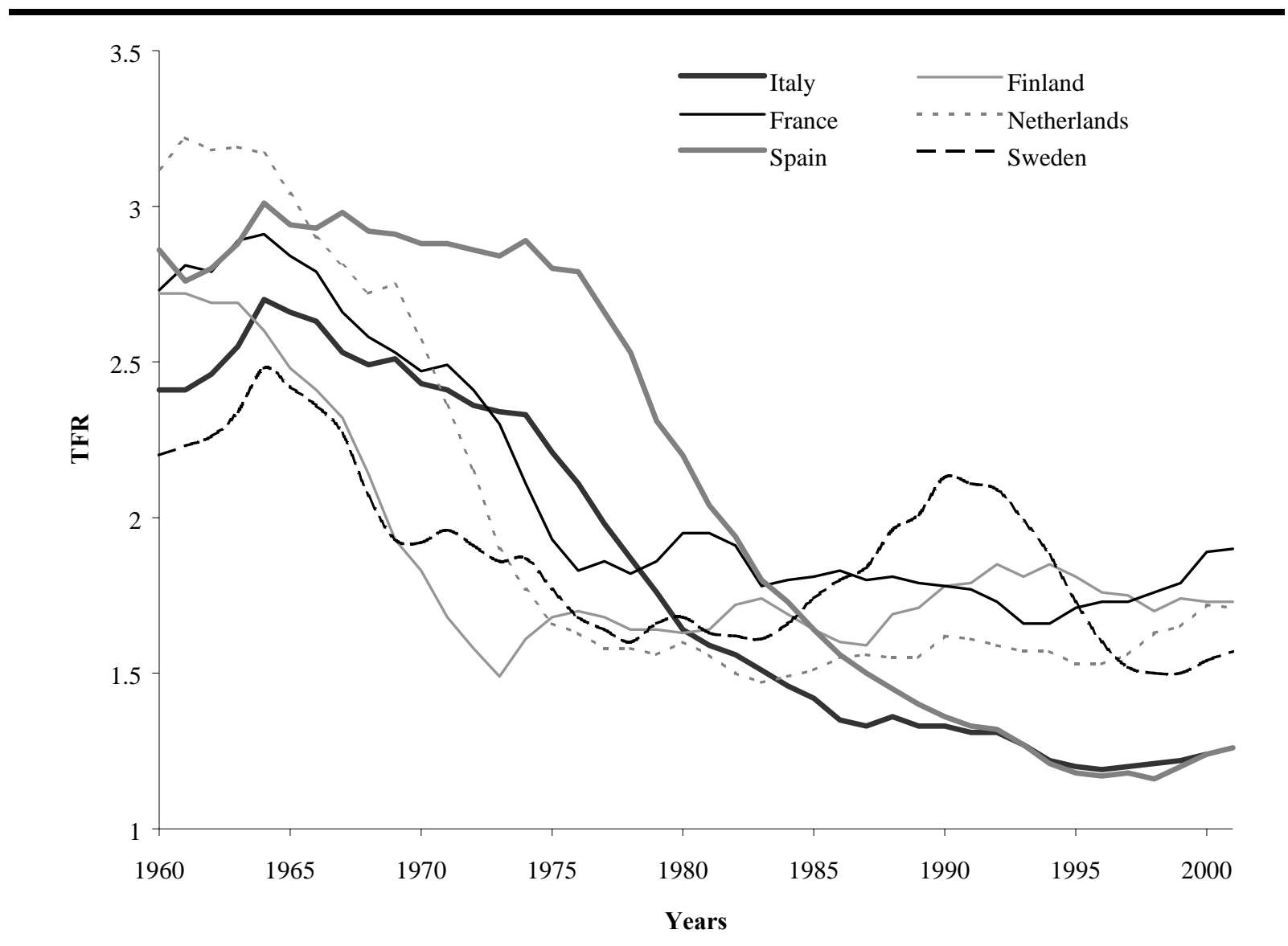

Source: Council of Europe - Demographic Yearbook 2002 


\begin{tabular}{|c|c|c|c|c|c|c|}
\hline & \multicolumn{2}{|c|}{$\begin{array}{c}\text { Model } 1 \\
\text { (Without } \\
\text { Heterogeneity) }\end{array}$} & \multicolumn{2}{|c|}{$\begin{array}{c}\text { Model } 2 \\
\text { (With } \\
\text { Heterogeneity) }\end{array}$} & \multicolumn{2}{|c|}{$\begin{array}{c}\text { Model } 3 \\
\text { (With Correlation) }\end{array}$} \\
\hline & $B$ & $S E$ & $B$ & $S E$ & $B$ & $S E$ \\
\hline \multicolumn{7}{|c|}{ Union stability } \\
\hline \multicolumn{7}{|c|}{$\begin{array}{l}\text { Marital duration: spline } \\
\text { (months) }\end{array}$} \\
\hline 0-36 months & 0.0139 & 0.0108 & 0.0175 & 0.012 & 0.0118 & 0.0113 \\
\hline 36-84 months & 0.0002 & 0.0067 & 0.0016 & 0.0069 & -0.0021 & 0.0071 \\
\hline 84-180 months & 0.0078 & $0.0033 * *$ & 0.0082 & $0.0035 * *$ & 0.0069 & $0.0034 * *$ \\
\hline d180+ months & -0.0098 & $0.0043^{* *}$ & -0.0096 & $0.0044 * *$ & -0.0099 & $0.0044^{* *}$ \\
\hline Constant & -8.1406 & $0.3403 * * *$ & -8.5621 & $0.6605 * * *$ & -8.6902 & $0.3555 * * *$ \\
\hline \multicolumn{7}{|l|}{ Age at first union $(<\mathbf{2 0})$} \\
\hline 20-22 years & -0.4667 & $0.1852 * *$ & -0.4784 & $0.2012 * *$ & -0.4896 & $0.1966 * *$ \\
\hline 23-25 years & -0.7269 & $0.2066^{* * *}$ & -0.7643 & $0.2262 * * *$ & -0.742 & $0.2218^{* * *}$ \\
\hline$>=26$ years & -1.0668 & $0.2642 * * *$ & -1.1275 & $0.2971 * * *$ & -1.1051 & $0.285^{* * *}$ \\
\hline \multicolumn{7}{|l|}{ Parents separation (No) } \\
\hline Yes, $<18$ years & 1.3072 & $0.2712 * * *$ & 1.4101 & $0.3336^{* * *}$ & 1.3876 & $0.2998^{* * *}$ \\
\hline Yes, $>=18$ years & 0.0549 & 0.7343 & 0.068 & 0.7482 & 0.0387 & 0.7492 \\
\hline \multicolumn{7}{|l|}{ Education (Low level) } \\
\hline Medium level & 0.3564 & $0.1686^{* *}$ & 0.383 & $0.181 * *$ & 0.4255 & $0.1817^{* *}$ \\
\hline High level & 0.936 & $0.2606^{* * *}$ & 0.9639 & $0.2976^{* * *}$ & 0.9942 & $0.2863 * * *$ \\
\hline \multicolumn{7}{|c|}{ Type of Union (Marriage) } \\
\hline Cohabitation & 1.9149 & $0.2233 * * *$ & 2.046 & $0.2879 * * *$ & 2.15 & $0.2553 * * *$ \\
\hline \multicolumn{7}{|l|}{ Childbearing (Parity 0) } \\
\hline Parity 1 & -0.6753 & $0.2018 * * *$ & -0.7199 & $0.214 * * *$ & -0.3845 & 0.2663 \\
\hline Parity 2 & -1.2925 & $0.26^{* * *}$ & -1.3954 & $0.2941^{* * *}$ & -0.7863 & $0.4368^{*}$ \\
\hline Parity 3 & -1.9798 & $0.4381 * * *$ & -2.0905 & $0.4638 * * *$ & -1.2557 & $0.622^{* *}$ \\
\hline \multicolumn{7}{|c|}{$\begin{array}{l}\text { Employment (Housewife }+ \\
\text { Others) }\end{array}$} \\
\hline Employed <35 hours & 0.4211 & 0.2843 & 0.4135 & 0.2957 & 0.4629 & 0.2952 \\
\hline Employed 35-44 hours & 0.4662 & $0.1893 * *$ & 0.4777 & $0.1963 * *$ & 0.5401 & $0.1962 * * *$ \\
\hline Employed 45+ hours & 0.8116 & $0.2168 * * *$ & 0.8198 & $0.2286^{* * *}$ & 0.8712 & $0.2298 * * *$ \\
\hline Self-Employed & -0.0399 & 0.3375 & 0.0098 & 0.3536 & 0.0757 & 0.3532 \\
\hline Period (bef & & & & & & \\
\hline After 1988 & 0.4366 & $\begin{array}{r}0.164 * * * \\
\text { Fertili }\end{array}$ & 0.4567 & $0.1714^{* * *}$ & 0.4814 & $0.1705^{* * *}$ \\
\hline
\end{tabular}

Time since last birth: spline

\section{(months)}

$<12$ months

12-24 months

24-36 months

$>36$ months

Age: spline (years)

$<23$ years

23-28 years

$>28$ years

$\begin{array}{rlrlrl}0.1878 & 0.0091^{* * *} & 0.2184 & 0.0091 * * * & 0.2184 & 0.0092 * * * \\ -0.0324 & 0.0052^{* * *} & -0.0073 & 0.0055 & -0.0071 & 0.0055 \\ 0.0199 & 0.0045^{* * *} & 0.0384 & 0.0048^{* * *} & 0.0383 & 0.0048^{* * *} \\ -0.0172 & 0.0007^{* * *} & -0.0138 & 0.0008^{* * *} & -0.0139 & 0.0008^{* * *} \\ & & & & & \\ -0.0477 & 0.0071^{* * *} & -0.0483 & 0.0108^{* * *} & -0.0464 & 0.0107 * * * \\ -0.0596 & 0.0097^{* * *} & -0.0447 & 0.0125^{* * *} & -0.0458 & 0.0124 * * * \\ -0.0738 & 0.0128^{* * *} & -0.0672 & 0.0146^{* * *} & -0.067 & 0.0146 * * *\end{array}$




\begin{tabular}{|c|c|c|c|c|c|c|}
\hline $\begin{array}{l}\text { Constant } \\
\text { Cohort }(45-50)\end{array}$ & -4.5334 & $0.1887 * * *$ & -5.1002 & $0.2601 * * *$ & -5.1628 & $0.2593 * * *$ \\
\hline 1951-1955 & -0.0424 & 0.0325 & -0.0659 & 0.06 & -0.056 & 0.0599 \\
\hline 1956-1960 & -0.1313 & $0.0351^{* * *}$ & -0.2101 & $0.0631^{* * *}$ & -0.2051 & $0.063^{* * *}$ \\
\hline 1961-1965 & -0.1891 & $0.0379 * * *$ & -0.2925 & $0.0652 * * *$ & -0.2882 & $0.065 * * *$ \\
\hline 1966-1970 & -0.3393 & $0.0535^{* * *}$ & -0.4826 & $0.0807 * * *$ & -0.4804 & $0.0804^{* * *}$ \\
\hline 1971-1977 & -0.397 & $0.1177^{* * *}$ & -0.5064 & $0.1597^{* * *}$ & -0.4954 & $0.1596^{* * *}$ \\
\hline \multicolumn{7}{|l|}{ Education (Low level) } \\
\hline Medium level & -0.16 & $0.0299 * * *$ & -0.2927 & $0.05 * * *$ & -0.2949 & $0.05 * * *$ \\
\hline High level & -0.0432 & 0.0519 & -0.1974 & $0.0847 * *$ & -0.199 & $0.0847^{* *}$ \\
\hline \multicolumn{7}{|c|}{$\begin{array}{l}\text { Employment (Housewife + } \\
\text { Others) }\end{array}$} \\
\hline Employed $<35$ hours & -0.3686 & $0.0639 * * *$ & -0.5254 & $0.0866^{* * *}$ & -0.5206 & $0.0865 * * *$ \\
\hline Employed 35-44 hours & -0.5252 & $0.034 * * *$ & -0.6777 & $0.0479 * * *$ & -0.6784 & $0.0478 * * *$ \\
\hline Employed 45+ hours & -0.3648 & $0.0466^{* * *}$ & -0.5078 & $0.0673 * * *$ & -0.5063 & $0.0671^{* * *}$ \\
\hline Self-Employed & -0.4562 & $0.0673^{* * *}$ & -0.617 & $0.0921 * * *$ & -0.6199 & $0.0923 * * *$ \\
\hline \multicolumn{7}{|l|}{ Childbearing (Parity 0) } \\
\hline arity 1 & -1.0868 & $0.0344 * * *$ & -1.706 & $0.0506^{* * *}$ & -1.7088 & $0.0507^{* * *}$ \\
\hline Parity 2 & -2.1586 & $0.052 * * *$ & -3.2065 & $0.0753^{* * *}$ & -3.2084 & $0.0753^{* * *}$ \\
\hline Parity 3 & -2.2183 & $0.072 * * *$ & -3.7979 & $0.1048^{* * *}$ & -3.7997 & $0.1046^{* * *}$ \\
\hline \multicolumn{7}{|l|}{ Union dissolution (No) } \\
\hline Yes & -0.7598 & $0.1359 * * *$ & -0.8495 & $0.1581^{* * *}$ & -0.6375 & $0.1845^{* * *}$ \\
\hline \multicolumn{7}{|l|}{$\begin{array}{l}\text { Type of Union } \\
\text { (Cohabitation) }\end{array}$} \\
\hline Marriage & 0.9085 & $0.1009 * * *$ & 1.3101 & $0.1192 * * *$ & 1.3252 & $0.1193 * * *$ \\
\hline \multicolumn{7}{|c|}{ Unobserved heterogeneity } \\
\hline $\begin{array}{l}\text { Fertility } \varepsilon_{f} \\
\text { Unobserved heterog }\end{array}$ & & & 0.8281 & $0.0312^{* * *}$ & 0.8296 & $0.0312^{* * *}$ \\
\hline Stability $\varepsilon_{d}$ & & & 0.8077 & 0.5573 & 0.8077 & \\
\hline Correlation $\sigma$ & & & & & -0.4564 & $0.2416^{*}$ \\
\hline
\end{tabular}




\begin{tabular}{|c|c|c|c|c|c|c|}
\hline & $\begin{array}{r}\mathrm{M} \\
(\mathrm{W} \\
\text { Heter }\end{array}$ & $\begin{array}{l}\text { del } 1 \\
\text { ithout } \\
\text { geneity) }\end{array}$ & $\begin{array}{r}\mathrm{M} \\
\text { (With } \mathrm{He} \\
\end{array}$ & $\begin{array}{l}\text { del } 2 \\
\text { terogeneity) }\end{array}$ & $\begin{array}{r}\mathrm{M} \\
\text { (With C }\end{array}$ & $\begin{array}{l}\text { del } 3 \\
\text { orrelation) }\end{array}$ \\
\hline & $B$ & $S E$ & $B$ & $S E$ & $B$ & $S E$ \\
\hline \multicolumn{7}{|c|}{ Union stability } \\
\hline \multicolumn{7}{|c|}{$\begin{array}{l}\text { Marital duration: spline } \\
\text { (months) }\end{array}$} \\
\hline 0-36 months & 0.0287 & $0.0095 * * *$ & 0.0382 & $0.0128 * * *$ & 0.037 & $0.0102 * * *$ \\
\hline 36-84 months & 0.0043 & 0.0057 & 0.009 & 0.0067 & 0.008 & 0.0062 \\
\hline 84-180 months & -0.0075 & $0.0038 * *$ & -0.0069 & $0.0039 *$ & -0.0073 & $0.0039 *$ \\
\hline d180+ months & 0.006 & 0.0039 & 0.0063 & 0.004 & 0.0062 & 0.004 \\
\hline Constant & -8.3753 & $0.3279 * * *$ & -9.1425 & $0.717 * * *$ & -9.1809 & $0.3611^{* * *}$ \\
\hline \multicolumn{7}{|c|}{ Age at first union $(<20)$} \\
\hline 20-22 years & -0.6321 & $0.1749 * * *$ & -0.8013 & $0.2214 * * *$ & -0.8071 & $0.2051 * * *$ \\
\hline 23-25 years & -0.7576 & $0.1982 * * *$ & -0.9499 & $0.249 * * *$ & -0.9503 & $0.2287 * * *$ \\
\hline$>=26$ years & -0.6159 & $0.2374 * * *$ & -0.7983 & $0.2833 * * *$ & -0.7973 & $0.2786^{* * *}$ \\
\hline \multicolumn{7}{|l|}{ Parents separation (No) } \\
\hline Yes, $<18$ years & 0.5216 & $0.2849 *$ & 0.6025 & $0.347^{*}$ & 0.6035 & $0.3408 *$ \\
\hline Yes, $>=18$ years & 0.7826 & $0.4425 *$ & 0.7639 & 0.5275 & 0.7643 & 0.5332 \\
\hline \multicolumn{7}{|l|}{ Education (Low level) } \\
\hline Medium level & 0.4709 & $0.1657 * * *$ & 0.5754 & $0.2089 * * *$ & 0.5794 & $0.198 * * *$ \\
\hline High level & 0.3951 & 0.2609 & 0.4926 & 0.3159 & 0.5058 & 0.3135 \\
\hline \multicolumn{7}{|c|}{ Type of Union (Marriage) } \\
\hline Cohabitation & 2.3451 & $0.1881 * * *$ & 2.6905 & $0.3117 * * *$ & 2.7249 & $0.2321 * * *$ \\
\hline \multicolumn{7}{|l|}{ Childbearing (Parity 0) } \\
\hline Parity 1 & -0.2312 & 0.2019 & -0.3335 & 0.2252 & -0.2541 & 0.2606 \\
\hline Parity 2 & -0.9454 & $0.2676^{* * *}$ & -1.138 & $0.307 * * *$ & -0.9976 & $0.3574^{* *}$ \\
\hline Parity 3 & -0.3929 & 0.3206 & -0.6201 & $0.367^{*}$ & -0.4245 & 0.4993 \\
\hline \multicolumn{7}{|c|}{$\begin{array}{l}\text { Employment (Housewife } \\
+ \text { Others) }\end{array}$} \\
\hline Employed $<35$ hours & 0.5198 & $0.2368 * *$ & 0.5665 & $0.2675 * *$ & 0.584 & $0.2667 * *$ \\
\hline Employed 35-44 hours & 0.4143 & $0.1731 * *$ & 0.4173 & $0.1867 * *$ & 0.4383 & $0.1884^{* *}$ \\
\hline Employed 45+ hours & 0.6809 & $0.225 * * *$ & 0.6318 & $0.2454 * *$ & 0.6488 & $0.2471^{* * *}$ \\
\hline Self-Employed & 0.5824 & 0.4304 & 0.4745 & 0.4655 & 0.4783 & 0.4664 \\
\hline \multicolumn{7}{|l|}{ Period (before 1988) } \\
\hline After 1988 & 0.257 & $0.1561^{*}$ & 0.2691 & 0.1717 & 0.2805 & 0.1707 \\
\hline & & Fertilit & & & & \\
\hline
\end{tabular}

Time since last birth: spline

\section{(months)}

$<12$ months

12-24 months

24-36 months

$>36$ months

Age at childbirth: spline

(years)

$<23$ years

$-0.0372$

0.1948

$-0.0272$

$0.0099 * * *$

0.2174

$0.01 * * *$

0.2174

$0.01 * * *$

$0.02550 .0047 * * *$

$\begin{array}{ll}-0.0074 & 0.0056\end{array}$

$-0.0074$

0.0397

0.0056

$-0.01630 .0008^{* * *}$

$\begin{array}{ll}0.0397 & 0.0049 * * *\end{array}$

$-0.0124$

$\begin{array}{lll}-0.0329 & 0.0109 * * * & -0.0\end{array}$

$\begin{array}{ll}-0.0331 & 0.0109 * * *\end{array}$

23-28 years

$-0.0566 \quad 0.0098^{* * *}$

$-0.0472 \quad 0.0122 * * *$ 


\begin{tabular}{|c|c|c|c|c|c|c|}
\hline$>28$ years & -0.1471 & $0.0144 * * *$ & -0.1403 & $0.0158^{* * *}$ & -0.1405 & $0.0158^{* * *}$ \\
\hline Constant & -4.9943 & $0.2117^{* * *}$ & -5.4947 & $0.2779 * * *$ & -5.4965 & $0.2776^{* * *}$ \\
\hline \multicolumn{7}{|l|}{ Cohort (45-50) } \\
\hline 1951-1955 & -0.1941 & $0.0351 * * *$ & -0.2355 & $0.0665 * * *$ & -0.2337 & $0.0665 * * *$ \\
\hline 1956-1960 & -0.2593 & $0.0366^{* * *}$ & -0.3129 & $0.0659 * * *$ & -0.3113 & $0.0658 * * *$ \\
\hline 1961-1965 & -0.4435 & $0.041^{* * *}$ & -0.5864 & $0.0687 * * *$ & -0.5858 & $0.0687 * * *$ \\
\hline 1966-1970 & -0.7103 & $0.0558 * * *$ & -0.89 & $0.0837 * * *$ & -0.8895 & $0.0838 * * *$ \\
\hline 1971-1977 & -0.2925 & $0.1025 * * *$ & -0.3477 & $0.1386^{* *}$ & -0.3465 & $0.1385 * *$ \\
\hline \multicolumn{7}{|l|}{ Education (Low level) } \\
\hline Medium level & -0.0952 & $0.0373^{* *}$ & -0.1798 & $0.058 * * *$ & -0.1813 & $0.0581 * * *$ \\
\hline High level & -0.1258 & $0.0673^{*}$ & -0.2742 & $0.1017^{* * *}$ & -0.2749 & $0.1017 * * *$ \\
\hline \multicolumn{7}{|c|}{ Employment (Housewife } \\
\hline Employed $<35$ hours & -0.5913 & $0.069 * * *$ & -0.7846 & $0.085^{* * *}$ & -0.7851 & $0.085^{* * *}$ \\
\hline Employed 35-44 hours & -0.5405 & $0.0373^{* * *}$ & -0.7259 & $0.0488^{* * *}$ & -0.7255 & $0.0488^{* * *}$ \\
\hline Employed 45+ hours & -0.6699 & $0.0583 * * *$ & -0.8346 & $0.0732 * * *$ & -0.8346 & $0.0731^{* * *}$ \\
\hline Self-Employed & -0.4449 & $0.099 * * *$ & -0.5501 & $0.1243 * * *$ & -0.549 & $0.1243 * * *$ \\
\hline \multicolumn{7}{|l|}{ Childbearing (Parity 0) } \\
\hline Parity 1 & -1.028 & $0.0364 * * *$ & -1.5191 & $0.0472 * * *$ & -1.5188 & $0.0472 * * *$ \\
\hline Parity 2 & -2.056 & $0.0524 * * *$ & -2.8839 & $0.0699 * * *$ & -2.8836 & $0.0699 * * *$ \\
\hline Parity 3 & -1.8782 & $0.0632 * * *$ & -3.1111 & $0.0847 * * *$ & -3.1105 & $0.0849 * * *$ \\
\hline \multicolumn{7}{|l|}{ Union dissolution (No) } \\
\hline Yes & -0.4001 & $0.1122 * * *$ & -0.4204 & $0.128 * * *$ & -0.3706 & $0.1477 * *$ \\
\hline \multicolumn{7}{|l|}{$\begin{array}{l}\text { Type of Union } \\
\text { (Cohabitation) }\end{array}$} \\
\hline Marriage & 1.2469 & $0.0912^{* * *}$ & 1.5793 & $0.1099 * * *$ & 1.5853 & $0.1104^{* * *}$ \\
\hline \multicolumn{7}{|c|}{ Unobserved heterogeneity } \\
\hline $\begin{array}{l}\text { Fertility } \varepsilon_{\mathrm{f}} \\
\text { Unobserved heterogen }\end{array}$ & & & 0.7143 & $0.0281^{* * *}$ & 0.7143 & $0.0282 * * *$ \\
\hline $\begin{array}{l}\text { Stability } \varepsilon_{\mathrm{d}} \\
\text { Correlation } \sigma\end{array}$ & & & 1.0927 & $0.3921 * * *$ & $\begin{array}{r}1.0927 \\
-0.0989\end{array}$ & 0.1629 \\
\hline
\end{tabular}

